\title{
Analysis of Injury Patterns of Motorcycle Riders Admitted to Teaching Hospital, Karapitiya, Sri Lanka
}

\author{
Samadhi DAH, Ruwanpura PR \\ Office of the Judicial Medical Officer, Teaching Hospital, Karapitiya, Sri Lanka.
}

\begin{abstract}
Introduction: The number of fatality and the disability due to motorcycle collisions is being increasing globally and most of them are preventable tragedies. Motorcycle riders are a major vulnerable group of road users and the severity of crashes could be dependent on several factors. The aim of this study is to study the characteristics of crashes and the injury pattern of motorcycle riders.
\end{abstract}

Methods: A cross-sectional descriptive prospective study was conducted on patients admitted to Teaching Hospital Karapitiya with a history of motorcycle crashes. Data on socio-demographic profile and different characteristics relevant to driver, vehicle, environment and road factors were collected and analysis of injuries was performed.

Results: The injury pattern and the characteristics of the motorcycle riders, including 461 riders and 197 pillion riders were analyzed. There is a male predominance in both groups. Accidents among riders are more prevalent in 20-34 age groups. There is bi-fold prevalence of the time of incident representing usual traffic peaks in the area. The $10 \%$ of drivers in our study did not possess a license and $24 \%$ of riders were drunk at the time of the accidents. Injuries, commonly the abrasions and lacerations were prevalent in both extremities and head area in both types of riders. Drivers are often encountered with severe injuries compared to the pillion riders with a significant difference.

Conclusions: Higher prevalence in age group of 20-34 years, and the male sex were identified. Injuries to limbs and head were common in both types of riders. Drivers are at the risk of sustaining more serious injuries than pillion riders in the study population. Continuous injury surveillance system and the enforcement of legal limit is recommended to minimize preventable incidents.

Keywords: Riders, Pillion, Injuries, Sri Lanka

Received: 02 Nov 2019, Revised version accepted: 20 Dec 2019, Published: 31 Dec 2019. *Corresponding author: Samadhi D.A.H, $\bigotimes$ email- dahsamadhid@gmail.com, iD ORCID https://orcid.org/0000-0003-4814-6255

Cite this article as: Samadhi DAH, Ruwanpura PR. Analysis of Injury Patterns of Motorcycle Riders Admitted to Teaching Hospital, Karapitiya, Sri Lanka. Medico-Legal Journal of Sri Lanka, 2019;7(2):42-50.

DOI: http://doi.org/10.4038/mljsl.v7i2.7398

Copyright: @ 2019 with the Medico-legal Journal of Sri Lanka.

This is an open-access article distributed under the terms of the Creative Commons Attribution 4.0 International License, which permits unrestricted use, distribution and reproduction in any medium provided the original author and source are credited.

\section{Introduction}

Road traffic injuries are a significant public health and development crisis worldwide. ${ }^{[1]}$ World Health Organization (WHO) indicates the road injury as the $10^{\text {th }}$ ranked global cause of death in 2016, which is predicted to be the $8^{\text {th }}$ in $2030 .{ }^{[2]}$ It has become a primary public hazard to humans which need to be handled in a multi-disciplinary manner. With the introduction of the open economic policy to Sri Lanka in 1977, a large number of three-wheelers and motorcycles were imported, which are recognized as the most susceptible vehicle types of roadside collisions. The number of fatalities and disabilities due to motor vehicle collisions are reported to be escalating day-by-day. ${ }^{[3]}$ The global estimations suggest that 23 to 24 million peoples are being injured annually ${ }^{[4]}$, while the death rate remains as high as 1.24 million throughout. ${ }^{[5]}$

Different studies have shown that the motorcycles account for the majority of roadside collisions. ${ }^{[6,7]}$ It is one of the most popular transport methods in Asian countries, including Sri Lanka, due to feasibility and low cost. The number of newly registered motorbikes per year in Sri Lanka is gradually increasing, and the total number was $1,760,600$ for 2008 compared to 2015 , where it was $33,59,501$ accounted for $53.3 \%$ of the total vehicle 
population. ${ }^{[8]}$ It is evident that the incidences of motorbike collisions are increasing proportionately to the number of registered motorbikes. The motorcycle riders are a major vulnerable group of road users due to lack of protection features provided by the motorbikes. ${ }^{[9]}$ Even with minor collisions, they tend to receive serious injuries. ${ }^{[10]} \mathrm{A}$ reckoning number of patients are admitted to casualty wards daily, and it is a considerable burden over the health care system, as well as to the family members.

Motorbike accidents and their severity could be dependent on factors related to motorbike riders, environment, characteristics of the motorbike, state of roads and many more. ${ }^{[1]}$ Injuries can be varying from minor to fatal injuries. Nevertheless, literature shows that the injuries are mostly confined to the head and the lower extremities. ${ }^{[12,13]}$

It is accepted that most of these accidents are in the predictable and preventable category ${ }^{[14]}$ and the necessary precautions can minimize the number of incidents. Despite its popularity and the broad usage, motorcycle collisions have received relatively lower attention by the research community and the available literature sources regarding motorbike accidents in Sri Lanka are very limited. The objective of this study is to investigate the characteristics of motorbike accidents and the injury patterns of the riders due to roadside crashes admitted to the teaching hospital, Karapitiya, Sri Lanka.

\section{Methods}

A cross-sectional descriptive prospective study was conducted on patients (motorcycle occupants) admitted to teaching hospital Karapitiya with a history of motorcycle crash from $1^{\text {st }}$ March to $31^{\text {st }}$ December 2018.

The informed written consent was given by the patients or by the next of kin accordingly or by the guardian in the case of a child to participate in the study. An interviewer-administered questionnaire was formulated to collect the data on sociodemographic profile, different characteristics relevant to driver, vehicle, environment and road factors prevailed at the time of collision, the type and site of the injury retrieved during the clinical forensic examination, hospital records, police records, imaging data etc. on a pre-tested datasheet. The severity of the injury was determined and categorized as non-grievous, grievous, endanger the life or fatal in the ordinary cause of nature. All nonconsenting patients and the patients who were unable to give information about the accident were excluded from the study. Ethical approval was obtained from the Ethical Review Committee,
Faculty of Medicine, University of Ruhuna. The data were analyzed using SPSS IBM version 22.

\section{Results}

After the data collection, there was a total of 658 motorcycle occupants of whom approximately twothird $(70 \%, n=460)$ were the riders, and the remaining $30 \%(\mathrm{n}=198)$ were the pillion riders.

\section{Socio-Demographic data}

Males $(78 \%)$ are often victimized than females $(22 \%)$. Sex ratio of pillion riders is 722 , while in drivers it is 122. The sex distribution is shown in Figure 01.

Figure 01: Sex distribution among the drivers and the pillion riders

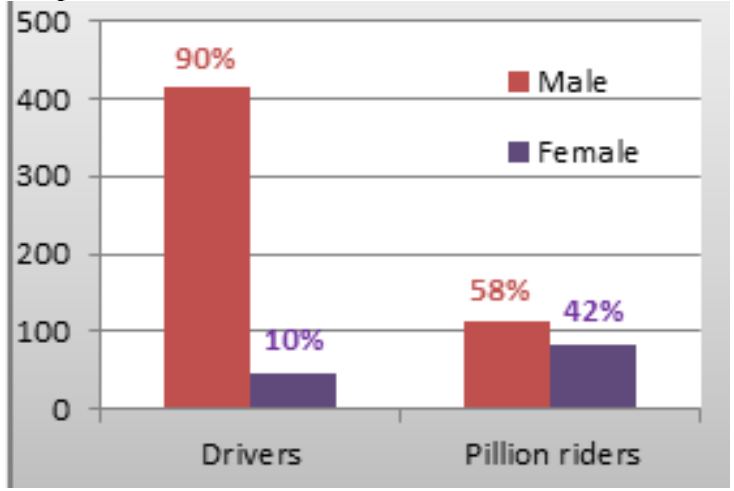

The highest number of victims falls within the 2034 years age group in our study. The age distribution is shown in Figure 02.

Figure 2: Age distribution of the drivers and the pillion riders



The motorcycle Riders who had the highest educational level (graduates) represented the lowest vulnerable group out of all the victims and the distribution is shown in Fig. 03. 
Figure 03: Education level of the riders

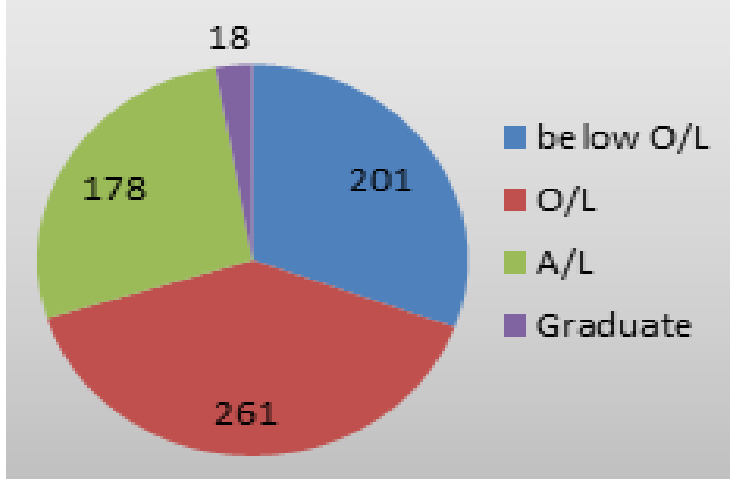

The motorcycle Riders who were with the highest monthly income (more than Rs.36, 000) represented the lowest vulnerable group out of all the victims and the distribution is shown in Fig. 04.

Figure 04: Monthly income of the riders

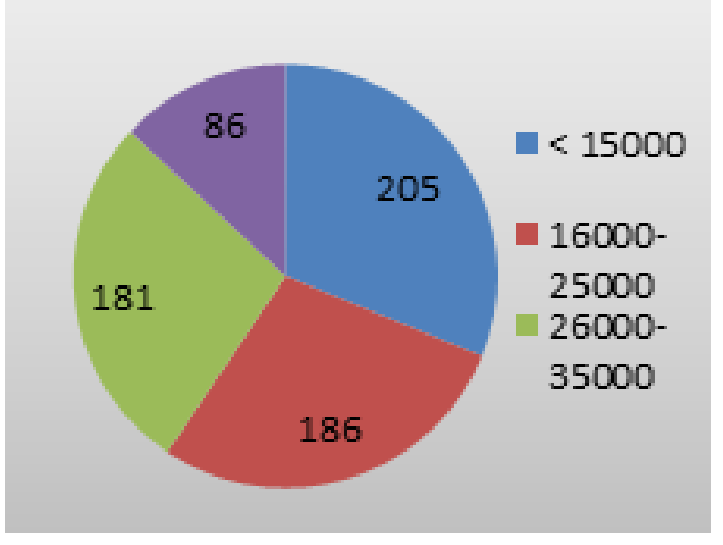

\section{Characteristics of motorcycle accidents}

There is no significant difference observed in the number of accidents reported during the weekend when compared to the number of accidents reported during the working days of the week and is illustrated in the Figure 05.

Figure 05: Number of accidents in relation to the day of the week

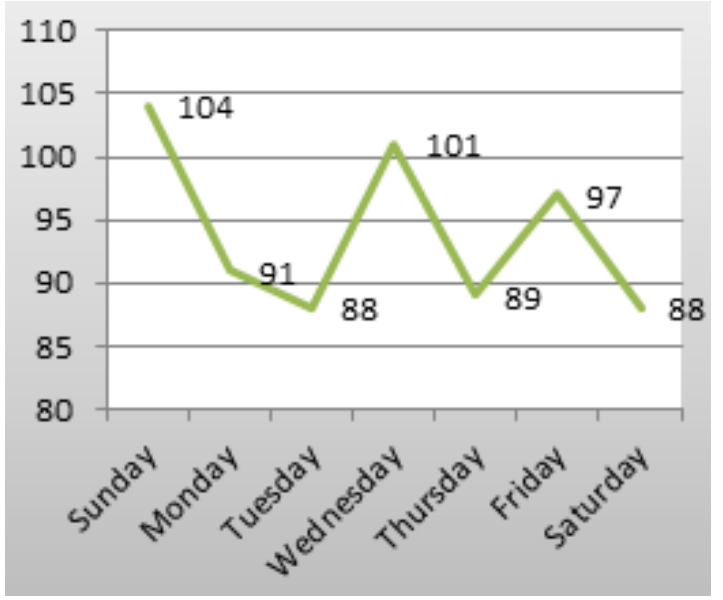

Most of the collisions are recorded during the daytime with several peaks. More than $35 \%$ of the accidents have taken place from $3 \mathrm{pm}$ to $7 \mathrm{pm}$ and are shown in Figure 06.

Figure 06: Time of the incident

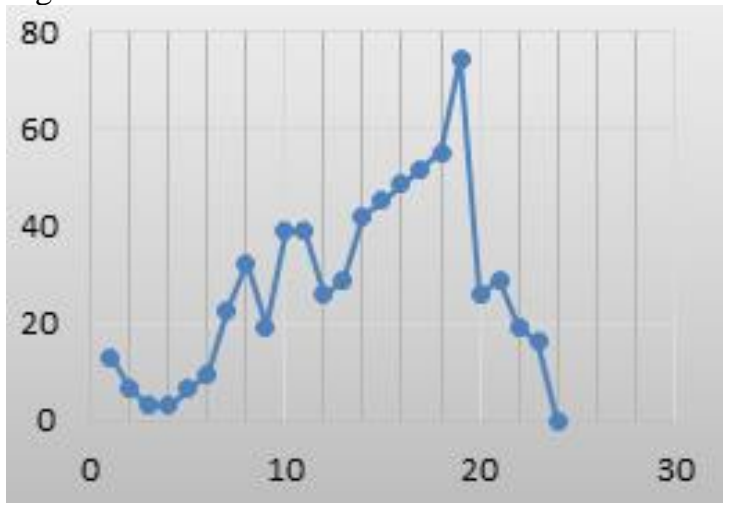

\section{Police area of the incident}

The 31 police areas, from where the accidents reported, were included in the study. Most of them belong to Galle district where 11 cases from outside the Galle area as the patients had been transferred from hospitals of other districts for specialized care. Out of total population ( $\mathrm{N}=658)$, the highest number of cases were reported from Galle police area $(n=133)$ followed by Habaraduwa $(n=98)$, Yakkalamulla $(n=82)$ and Akmeemana $(n=73)$ which are considered urban compared to other regions.

Table 01: Number of accidents in relation to the police areas

\begin{tabular}{lr}
\hline Police area & $\begin{array}{r}\mathrm{N}=658 \\
\%(\mathrm{n})\end{array}$ \\
\hline Galle & $20(133)$ \\
Habaraduwa & $15(98)$ \\
Yakkalamulla & $12(82)$ \\
Akmeemana & $11(73)$ \\
Baddegama & $07(48)$ \\
Rathgama & $05(35)$ \\
Others in Galle & $23153)$ \\
Others out of Galle & $05(36)$ \\
\end{tabular}

The majority (53\%) is injured due to collision between two vehicles (including motorcycle) and the distribution is illustrated in Figure 07. 
Figure 07: Type of collisions

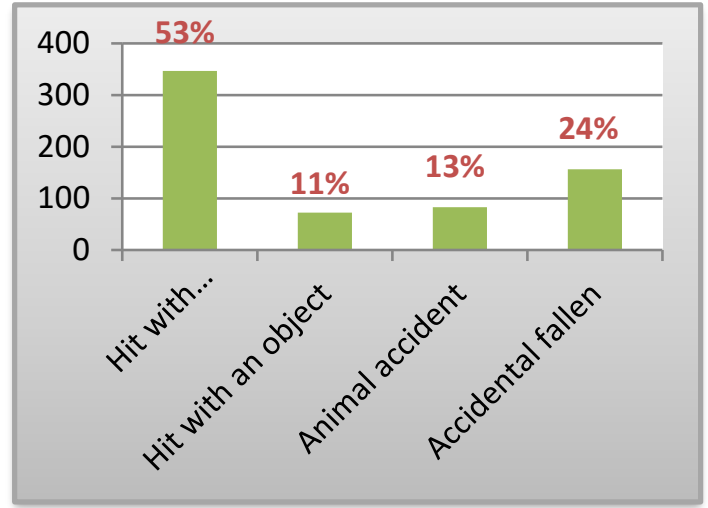

Classical and the moped types of bikes are commonly used by the males in our study where scooter bikes are popular among females and they are illustrated in Figure 08.

Figure 08: Type of motorbike with the sex distribution

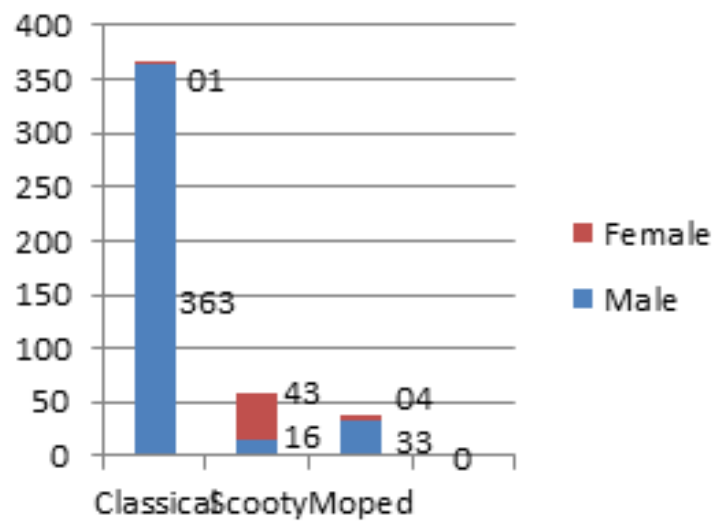

Majority of the accidents $(95 \%)$ had been occurred with travelling speed of $40-60 \mathrm{~km} / \mathrm{h}^{-1}$ at the time of the collision. The motorbikes in the study were recently registered (<5years) $(43 \%)$ and mechanical defects had been reported only in $23(3 \%)$ motorbikes; mainly associated with defective breaking (11) and side mirror problems (08).

The motorbike accidents in the study had occurred mainly in tar roads (44\%) followed by carpeted roads $(27 \%)$ and the highest percentage of cases was reported under the precise weather conditions. $70 \%$ of the riders have worn helmets at the time of injury in our study. $24 \%$ of victims in our study found to be consumed alcohol one to four hours before the time of the accident. There were $47(10 \%)$ of drivers without a valid license among the driver group. These findings are shown in Table 02.
Table 02: Different aspects of the motorcycle crash incident

\begin{tabular}{llr}
\hline Incident & N=658 \\
\%oad Type & Carpeted & $27(175)$ \\
& Tar & $44(292)$ \\
& Concrete & $16(105)$ \\
& Gravel & $13(86)$ \\
Whether & Clear & $56(366)$ \\
& Rainy & $38(249)$ \\
& Misty & $07(43)$ \\
Use of helmet & Yes & $70(461)$ \\
& No & $30(197)$ \\
Alcohol use & Yes & $24(109)$ \\
& No & $76(352)$ \\
License to ride & Yes & $90(414)$ \\
& No & $10(47)$ \\
& &
\end{tabular}

Injury pattern of the drivers and the pillion riders

Damages to the lower limbs followed by upper limbs and head areas are the commonly involved anatomical sites of the body in both drivers and pillion riders. The sites of the injuries are shown in Figure 09.

Figure 09: Anatomical areas involved among drivers and pillion riders

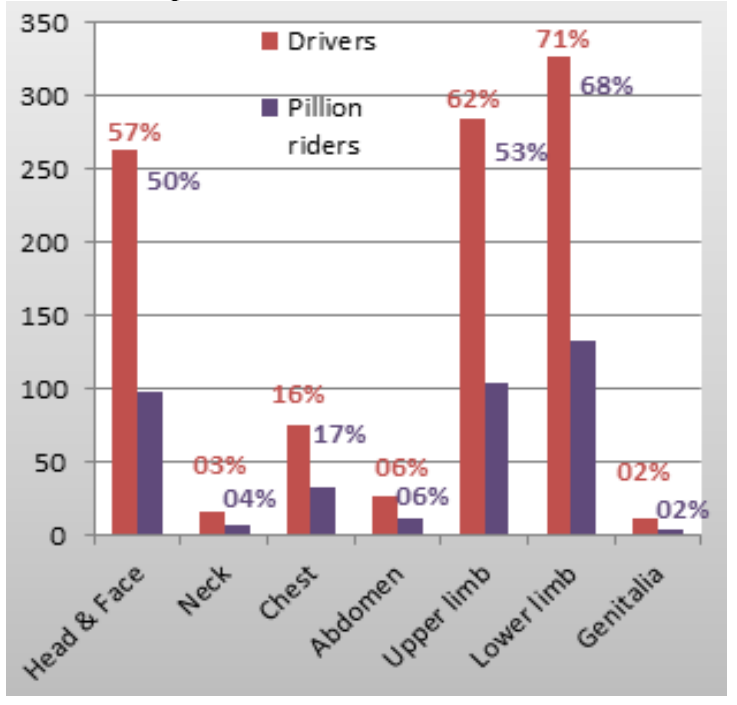

The commonest type of injury sustained by both drivers and the riders are abrasions followed by laceration and fractures. Types of injuries are shown in Figure 10. 
Figure 10: Type of injury among drivers and pillion riders

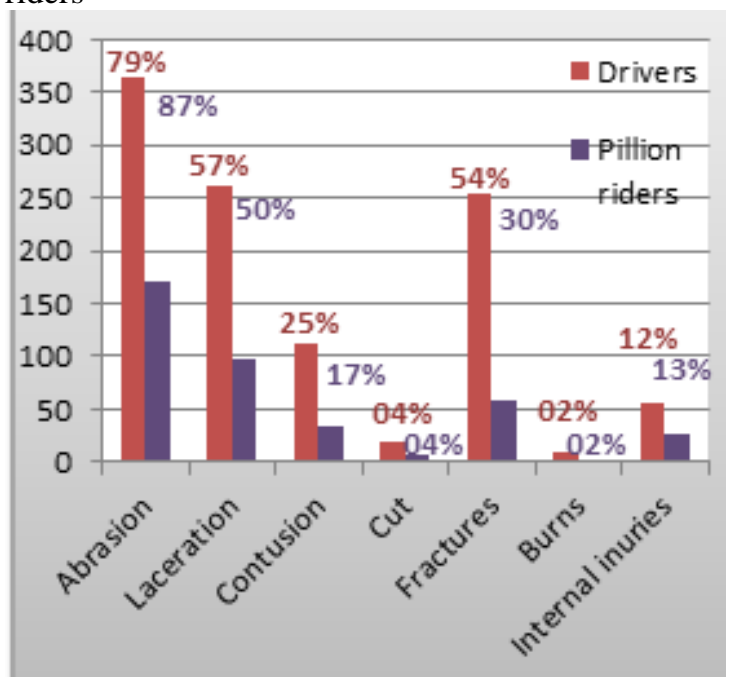

Most of the drivers in the study have suffered grievous injuries, while the pillion riders are prevalent received non-grievous injuries. The categories of hurt are shown in Figure 11.

Figure 11: Categorization of injuries in both riders and the pillion riders

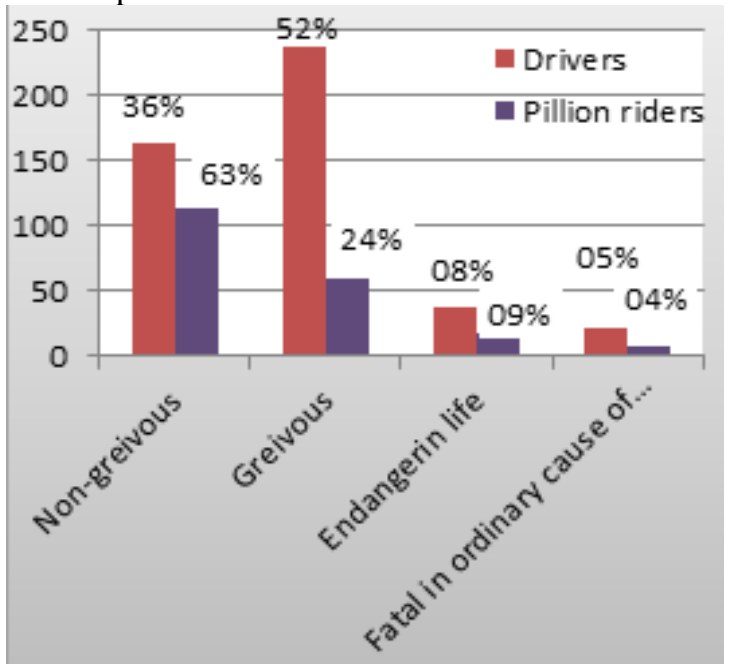

There is a significant difference in the severity of injuries between the drivers and the pillion riders when all the categories of injuries are considered $(\mathrm{p}<.05)$.

Comparison of the two groups of riders according to the injury severity; was assessed by grouping them in to (a) Category of non-grievous injuries and (b) Category of grievous injuries and above.
Table 03: Category of injuries among the riders and the pillion riders

\begin{tabular}{lrr}
\hline & $\begin{array}{r}\text { Non- } \\
\text { grievous } \\
\text { \% (n) }\end{array}$ & $\begin{array}{r}\mathbf{N = 6 5 8} \\
\text { Grievous and above } \\
\text { \% (n) }\end{array}$ \\
\hline Riders & $31(142)$ & $69(319)$ \\
Pillion R & $57(113)$ & $43(84)$
\end{tabular}

The chi-square statistic is 41.014 , and this results in a significant difference between two groups of riders with the severity of the injury $(\mathrm{p}<.05)$.

\section{Discussion}

Motorcyclists, along with pedal cyclists and pedestrians, account for the majority of vulnerable road users and contribute to more than half of the deaths due to roadside trauma worldwide. ${ }^{[15]}$ Irrespective of the model of the motorbike, higher incidence of crashes and the injury severity are strongly co-relate with lack of its protective shell with the absence of modern protective features such as seat belts, airbags etc. and also the lesser stability of the motorcycle. Nevertheless, motorcycles are still a popular mode of transportation, especially in developing countries like Sri Lanka and the number of motorcycles on the roads is being continuously rising.

This study is focused on the injury pattern, and the characteristics of motorcycle riders admitted to Teaching hospital Karapitiya, Sri Lanka over consecutive ten month's duration in 2018 following motorbike accidents. Drivers and the pillion riders are separately analyzed and compared in sections of the study.

There is a male predominance in both groups on our study, but the injured female proportion is significantly higher among pillion riders (42\%) compared to riders (10\%). Several studies done in Sri Lanka, as well as global statistics, show the same vulnerability of males while being the commonest users ${ }^{[16]}$. It has been observed that the number of female drivers is drastically rising worldwide over the last couple of years with the introduction of userfriendly female conventional bicycles. ${ }^{[17]}$ It is revealed in our study that injured female scooty-bike drivers are three-fold higher than the males.

A significantly higher number of drivers lie within 20 -34 years age group in our study, followed by the 35 to 49 years age group. Similar results are seen in the previous studies conducted in Sri Lanka in relation to all accidents, ${ }^{[15.16]}$ and also in both developing and developed countries, e.g. Nigeria, ${ }^{[18]}$ Turkey ${ }^{[19]}$ with some minor differences, indicating the need of targeted educational and enforcement approach especially towards this age groups. 
Education level and the monthly income of the victims were analyzed for the completion. It was found that the highest number of victims had just completed the ordinary level examination, and the results coincided with the age groups as well, that indicates the necessity of further guidance regarding the safe use of the roads. Less number of victims with higher education and higher income level suggests could either be due to comparatively lower prevalence of usage of motorcycles or the better roadside attitudes among higher-income groups. However, this aspect needs further targeted studies to make reliable conclusions.

There was no significant difference in the number of casualties according to the day of the week. On the other hand, the findings may not reflect the real number of accidents as there is a possibility of involving several victims in the same accident. The analysis of the time of the accidents in this study is in keeping with the expected values according to the vehicle density of the areas of the incidents. There bi-fold pattern of frequency in our study, from $4 \mathrm{pm}$ to $8 \mathrm{pm}$ and 7 am to 9 am representing afternoon and morning peaks of average daily traffic (ADT), ${ }^{[20]}$ and there is another minor peak in the morning in between 10 am to 11 am which is difficult to explain. There is a theoretical possibility that 10 to $11 \mathrm{am}$ peak could be due to that more motorcycle users from non-urban distant areas are entering into the roads during this time.

The most common mechanism of causation of injuries to the motorcycle occupants in our study is a collision with another vehicle. A study done in Nigeria on motorcycle riders has shown the same feature prominence with $48 \%{ }^{[18]}$ prevalence and also in a study done in Saudi Arabia ${ }^{[21]}$, a collision between two motorcyclists is recognized as a major cause. However, regardless of the type of vehicle involved, the human factor is regarded as the universally admitted commonest contributory reason for road-side trauma. ${ }^{[22]}$ Drunk driving, driving without a license, non-adherence to protective clothing including helmets and excessive speed are on the top of the list of human errors in Sri Lanka as well, ${ }^{[16]}$ and in line with the findings in other countries. ${ }^{[23,24]}$

In our study, 24\% $(n=109)$ of drivers had consumed liquor at the time of the accident. In fact, consumption of alcohol by the riders of this case series has been diagnosed by clinical signs, which are non-specific and vague at times and the real number of drivers who had consumed alcohol could have been higher than $24 \%$. Though it is possible to determine the accurate alcohol level with invasive investigations like with blood alcohol concentration (BAC), it was not applied in this study due to the practical and technical issues. However, the estimation of alcohol levels with non-invasive modern electronic devices is now being introduced to the medico-legal units of state hospitals in Sri Lanka and will be an advantage for future studies. The studies done in Sri Lanka on postmortem samples of victims of fatal accidents have shown that more than one-third of drivers had exceeded the legal limit of alcohol. ${ }^{[25]}$

In our study, 30\% $(\mathrm{n}=197)$ were riding without helmets at the time of the collision. Approximately more than $50 \%$ of riders of low and middle-income countries do not wear helmets despite the legislation that mandated the helmet usage. ${ }^{[26]}$ National Highway Traffic Safety Administration (NHTSA) has emphasized the importance of proper helmet usage according to international helmet laws based on analysis of fatal motorcycle crashes in USA, ${ }^{[27]}$ and the fact of the proper helmet usage and the reduction of head injury and its severity is well established in the literature. ${ }^{[26,28]}$ However, there is no significant difference between the presence of external head injury in helmeted and non-helmeted groups in our study, but $83 \%$ of internal head injuries were seen with non-helmeted riders. The fact of the use of helmet by the riders of this study has been determined by the Police investigation records as well as some characteristic injuries to the chin due to the buckle of the helmet strap.

Almost all the victims in our study population (97\%) stated that the speed of the vehicle in between 40 $55 \mathrm{~km} / \mathrm{h}$ falls within the legally accepted driving speed limit, though the reliability of victim statements are quite questionable without other independent eye witness account or other evidence. It causes difficulty in interpreting the impact of speed on the severity of injuries.

Most of the accidents in our study has been occurred in properly asphalt laden roads (44\%). This factual finding may vary from country to country according to their road conditions, availability etc. In a German study, it has been found that number accidents are higher on their highways ${ }^{[29]}$, probably associated with unlimited speed regulations. Although the rainy and moist weathers conditions elevate the risk of roadside trauma, in our study, most of the $(56 \%)$ the accidents were taken place under good weather conditions.

Lower limbs are the most typical site which had injured in both riders $(71 \%)$ and pillion riders $(68 \%)$, in the study followed by injuries to upper limb and head and face area. The findings of our study coincide with the other studies on motorcycle riders concerning the anatomical sites. Almost all studies have shown the extremity injuries as the commonest. ${ }^{[30,31]}$ 
Abrasions are the most frequent type of injury sustained by both type of riders in our study, followed by lacerations. A higher proportion of fractures are seen in drivers than in pillion riders, mainly involving extremities. The pneumocranium, extradural haemorrhage, intracerebral haemorrhages and pneumothorax are the often found other internal injuries in both types of riders. A Japanese study pertaining to the injury pattern of Racing motorbike drivers revealed that the fractures are the most prevalent type of grievous injury among victims. ${ }^{[32]}$

In our study showed that there is a significantly higher chance of receiving severe injuries in drivers than in pillion riders. Some studies have shown the results contradictory to our observations, ${ }^{[33]}$ while some shows no such significant difference. ${ }^{[34,35]}$ Conversely some studies have shown a higher incidence of run-over injuries in drivers than in pillion riders, while getting more fatal injuries due to tumbling effect is higher in riders in pillion position. ${ }^{[33]}$ The fine knowledge about different injury patterns will be essential for the clinical management of the patients and may also guide to distinguish the drivers from pillion riders in motorcycle crashes.

\section{Conclusions}

Higher prevalence in number of victims is seen in age group of 20-34 years, and the male sex were identified. Injuries to limbs and head were common in both types of riders. Riders are at the risk of sustaining more serious injuries than pillion riders in the study population. The demographic data of the victims and anatomical locations of injuries are in keeping with the findings of previous research from other countries. However, the injury pattern of riders and pillion riders showed significant variations where riders have suffered more severe lesions contrary to case series from other countries. The effect of alcohol and the use of helmet did not show significant changes in the injury patterns and needed to be studied further before arriving at firm conclusions. Continuous injury surveillance system and the enforcement of legal limit is recommended to minimize preventable incidents.

\section{Recommendations}

In order to avoid the preventable motorcycle crashes and to minimize the severity of victimization, the following recommendations become relevant; (a) Injury surveillance system with the continuous collection, analysis and storage of the facts about motorcycle crashes to ensure accurate national database, (b) mandatory use of helmets and other protective clothes, (c) enforcement of the legal limits and adherence to them, eg. Blood alcohol concentration, the limit of the speed, number of passengers carrying, speed limits etc, and (d) a motorcyclist should be continuously followed up with medical checkups, updated license and fitness trials.

\section{Disclosure statement}

Conflicts of interests: The authors declare that they have no conflicts of interests.

Funding: None

\section{References}

1. World health organization. The top 10 causes of death [Internet]. 2018 [Updated 2018; cited 2018 Mar 5]. Available from: http://www.who.int/medicentre/f actsheets/fs310/en/

2. Gopalakrishnan S. A public health perspective of road traffic accidents. Journal of family medicine and primary care. 2012 Jul;1(2):144.PMCID:PMC3893966

3. Feldkamp G, Junghanns K. The typical traffic accidents in adolescents: the motorcycle accident-some epidemiologic features and the effectiveness of safety helmets and clothing. In Proceedings of the International Research Council on the Biomechanics of Injury conference. International Research Council on Biomechanics of Injury.1976; 4(issue):75-80. PMID-1234203

4. Anantharaman V, Logaraj M. Epidemiology of Road Traffic Accidents (RTA) Reported at a Tertiary care hospital in Chennai. National $\mathbf{J}$ Res Community Med. 2015 Jan;4(1):101-5.

5. Amarasingha N. Characteristics of ThreeWheeler Crashes. Sri Lanka Institute of Information Technology.Sri Lanka,2015

6. Chalya PL, Mabula JB, Dass RM, Mbelenge N, Ngayomela IH, Chandika AB, Gilyoma JM. Injury characteristics and outcome of road traffic crash victims at Bugando Medical Centre in Northwestern Tanzania. Journal of trauma management \& outcomes. 2012 Dec;6(1):1.PMID-22321248

7. Department of motor traffic total vehicle population 2008-2015[ internet]2019 [updated on February 2016]Available from http://www.motortraffic.gov.lk/web /images/stories/document/pop2015.pdf

8. Edirisinghe PA, Kitulwatte ID, Senarathne UD. Injuries in the vulnerable road user fatalities; a study from Sri Lanka. Journal of forensic and legal medicine. 1;272014 Oct :9-12.PMID25287792

9. AMIR A, KHALIL S, HRUL HUDA MO. Road Traffic Injuries among Drivers and Pillion Riders using Two-Wheeler Motorized Vehicle in Western Uttar Pradesh. Journal of Clinical \& 
Diagnostic Research. 2018 Aug 1;12(8).p1-3. 3p. 4 Charts.

10. Schepers JP, Kroeze PA, Sweers W, Wüst JC. Road factors and bicycle-motor vehicle crashes at unsignalized priority intersections. Accident Analysis \& Prevention. 2011 May 1;43(3):85361. PMID-21376876

11. Oluwadiya KS, Kolawole IK, Adegbehingbe OO, Olasinde AA, Agodirin O, Uwaezuoke SC. Motorcycle crash characteristics in Nigeria: implication for control. Accident Analysis \& Prevention. 2009 Mar 1;41(2):294-8.PMID19245888

12. Heydari ST, Maharlouei NN, Foroutan A, Sarikhani Y, Ghaffarpasand F, Moafian G, Aghabeigi MR, Peymani P, Ahmadi SM, Dehghankhalili M, Joulaei H. Fatal motorcycle accidents in Fars Province, Iran: a communitybased survey. Chinese journal of traumatology. 2012 Aug 1;15(4):222-7.PMID-22863339

13. Behera C, Col L, Rautji R, Lalwani S, Dogra TD. A comprehensive study of motorcycle fatalities in South Delhi. J Indian Acad Forensic Med. 2007;31(1):6-10.

14. Mohan D. Road accidents in India. IATSS research. 2009 Jan 1;33(1):75.

15. Edirisinghe PA, Kitulwatte ID, Senarathne UD. Injuries in the vulnerable road user fatalities; a study from Sri Lanka. Journal of forensic and legal medicine. 2014 Oct 1;27:9-12.PMID25287792

16. Fernando DM, Tennakoon SU, Samaranayake AN, Wickramasinghe M. Characteristics of road traffic accident casualties admitted to a tertiary care hospital in Sri Lanka. Forensic science, medicine, and pathology. 2017 Mar 1;13(1):44-51.PMID-28019001

17. Langford BC, Chen J, Cherry CR. Risky riding: Naturalistic methods comparing safety behaviour from conventional bicycle riders and electric bike riders. Accident Analysis \& Prevention. 1;822015 Sep:220-6.

18. Oluwadiya KS, Kolawole IK, Adegbehingbe OO, Olasinde AA, Agodirin O, Uwaezuoke SC. Motorcycle crash characteristics in Nigeria: implication for control. Accident Analysis \& Prevention. 2009 Mar 1;41(2):294-8.

19. Durak D, Fedakar R, Türkmen N, Akgöz S, Baduroğlu E. Road traffic collisions in Bursa, Turkey, during 2003, 2004 and 2005. Injury. 2008 May 1;39(5):547-53.PMID-18054020

20. Das A, Abdel-Aty MA. A combined frequency-severity approach for the analysis of rear-end crashes on urban arterials. Safety Science. 2011 Oct 1;49(8-9):1156-63.

21. Ansari S, Akhdar F, Mandoorah M, Moutaery K. Causes and effects of road traffic accidents in Saudi Arabia. Public health. 2000 Jan 1;114(1):37-9.PMID-10787024
22. Singh H, Dhattarwal SK. Pattern and distribution of injuries in fatal road traffic accidents in Rohtak (Haryana). JIAFM. 2004;26(1):20-3.

23. Gboyega A, Ebijuwa AS, Oyetola SO, Akinola JO. Factors influencing the high rate of commercial motorcycle accidents in Nigeria. American International Journal of Contemporary Research. 2012;2(11):13040.PMID-19143162

24. Sreedharan J, Muttappillymyalil J, Divakaran B, Haran JC. Determinants of safety helmet use among motorcyclists in Kerala, India. Journal of injury and violence research. 2010 Jan;2(1):49.214831. PMID-21483198

25. Senarathne UD, Edirisinghe PA, Kitulwatte ID. Blood alcohol concentration in motorcycle fatalities reported to a tertiary care hospital in Sri Lanka.PMID-24341667

26. Macpherson A, Spinks A. Cochrane review: Bicycle helmet legislation for the uptake of helmet use and prevention of head injuries. Evidence-Based Child Health: A Cochrane Review Journal. 2008 Mar;3(1):16-32.PMID18646128

27. Centres for Disease Control and Prevention (CDC. Helmet use among motorcyclists who died in crashes and economic cost savings associated with state motorcycle helmet laws-United States, 2008-2010. MMWR. Morbidity and mortality weekly report. 2012 Jun 15;61(23):425.PMID-22695381

28. Sung KM, Noble J, Kim SC, Jeon HJ, Kim JY, Do HH, Park SO, Lee KR, Baek KJ. The preventive effect of head injury by helmet type in motorcycle crashes: a rural Korean singlecentre observational study. BioMed research international. 2016; vol (issue): pages. PMID27340652

29. Wick M, Müller EJ, Ekkernkamp A, Muhr G. The motorcyclist: easy rider or easy victim? An analysis of motorcycle accidents in Germany. The American journal of emergency medicine. 1998 May 1;16(3):320-3.PMID-9596444

30. Peek-Asa C, Kraus JF. Injuries sustained by motorcycle riders in the approaching turn crash configuration. Accident Analysis \& Prevention. 1996 Sep 1;28(5):561-9.PMID-8899037

31. Alicioglu B, Yalniz E, Eskin D, Yilmaz B. Injuries associated with motorcycle accidents. ActaOrthopTraumatolTurc. 2008 Mar 1;42(2):106-11.PMID-18552531

32. Tomida Y, Hirata H, Fukuda A, Tsujii M, Kato $\mathrm{K}$, Fujisawa K, Uchida A. Injuries in elite motorcycle racing in Japan. British journal of sports medicine. 2005 Aug 1;39(8):50811.PMID-16046332

33. Peden M. World report on road traffic injury prevention.PMID-15610629 
34. Zhao H, Chen R, Deng G, Yin Z, Yang G, Liu $\mathrm{S}$, Chen H, Wang Z. Comparison of injuries sustained by drivers and pillion passengers in fatal head-on motorcycle collision accidents. Forensic science international. 2011 Apr 15;207(1-3):188-92.PMID-21030167

35. Chiang VX, Cheng JY, Zhang ZC, Teo LT. Comparison of severity and pattern of injuries between motorcycle riders and their pillions: A matched study. Injury. 2014 Jan 1;45(1):3337.PMID-23473267

36. Fitzharris M, Dandona R, Kumar GA, Dandona L. Crash characteristics and patterns of injury among hospitalized motorised two-wheeled vehicle users in urban India. BMC public 